\title{
APTIDÃO AGRÍCOLA DO MUNICÍPIO DE SANTA LÚCIA - SP
}

\author{
AGRICULTURAL CAPABILITY IN SANTA LUCIA-SP COUNTY
}

\section{Henrique Aio Adorno', Afonso Assalin Zorgetto2, \\ Diego Peruchi Trevisan ${ }^{3}$, Luiz Eduardo Moschini ${ }^{4}$, Andréia Márcia Cassiano ${ }^{5}$}

\author{
Recebido em: 23 de dezembro de 2016 \\ Aprovado em: 17 de abril de 2017 \\ Sistema de Avaliação: Double Blind Review \\ RCO | a. 9 | v. 2 | p. 51-65 | jul./dez. 2017
}

\begin{abstract}
RESUMO
A elaboração de um zoneamento para o setor agrário é de suma importância para a expansão da produção agrícola, e consequente cultivo de matérias primas, a fim de fomentar o expansível mercado consumidor. O objetivo deste trabalho foi realizar a análise da aptidão agrícola do município de Santa Lúcia - SP, com a utilização de Sistemas de Informação Geográficas no intuito de definir as áreas potenciais para o desenvolvimento de tais atividades. A integração das informações de declividade, pedologia e uso e cobertura da terra ocorreu através do software Arcgis 10.3. Por meio da lógica Fuzzy gerou-se classes equiparativas dos dados analisados, resultando no mapa de aptidão agrícola da área de estudo que propôs as melhores áreas para o desenvolvimento de atividades agrícolas. O mapa de aptidão agrícola do município de Santa Lúcia - SP permitiu analisar que grande parte de sua extensão territorial possui uma aptidão agrícola alta e média. Os locais que possuem restrições legais ou que possuem baixa aptidão para plantio devem receber um reordenamento de seus usos do solo, destinando-se para o desenvolvimento áreas de recuperação ambiental.
\end{abstract}

Palavras-chave: Planejamento agrícola. Uso e cobertura da terra. Planejamento ambiental.

\begin{abstract}
The elaboration of a zoning for the agrarian sector is of paramount importance for the expansion of the agricultural production, and consequent cultivation of raw materials, in order to foment the expandable consumer market. The objective of this work was to analyze the agricultural aptitude of the municipality of Santa Lúcia - SP, with the use of Geographic Information Systems in order to define the potential areas for the development of such activities. The integration of slope, pedology, and land use and coverage information was achieved through Arcgis 10.3 software. Through Fuzzy Logic, were generated classes of the analyzed data, resulting in the map of agricultural aptitude of the study area that proposed the best areas for the development of agricultural activities. The map of agricultural aptitude of the municipality of Santa Lucía - SP allowed to analyze that great part of its territorial extension has a high and average agricultural aptitude. Locations that have legal restrictions or that have low planting ability should receive a rearrangement of their land uses, earmarked for the development of environmental recovery areas.

Keywords: Agricultural planning. Use and land cover. Environmental planning.

\footnotetext{
${ }^{1}$ Graduando em Gestão e Análise Ambiental pela Universidade Federal de São Carlos (São Carlos/Brasil). E-mail: henriaio1204@gmail.com.

${ }^{2}$ Graduando em Gestão e Análise Ambiental pela Universidade Federal de São Carlos (São Carlos/Brasil). E-mail: af.assalin@gmail.com.

3 Mestre em Ciências Ambientais pela Universidade Federal de São Carlos (São Carlos/Brasil). E-mail: diego.peruchi@gmail.com.

4 Doutor em Ecologia e Recursos Naturais pela Universidade Federal de São Carlos (São Carlos/Brasil). E-mail: lemoschini@ufscar.br.

${ }^{5}$ Doutora em Ciências da Engenharia Ambiental pela Universidade de São Paulo (São Carlos/Brasil). Professora na Universidade Federal de São Carlos (São Carlos/Brasil). E-mail: andreiacassiano@yahoo.com.br.
} 


\section{INTRODUÇÃO}

As atividades agrícolas sempre foram relevantes para a economia brasileira, possuindo papel ainda mais meritório devido ao reconhecimento do etanol como alternativa aos combustíveis fósseis, ao fortalecimento do preço do açúcar no mercado e a valorização de subprodutos advindos de processos industriais resultantes da síntese de açúcar e álcool (GOES, 2008, p.40).

Entretanto, o avanço de monoculturas, destinadas majoritariamente à produção de commodities, são frequentemente relacionadas com a deterioração dos recursos naturais, sendo mais facilmente notadas nas áreas rurais onde ocorrem tais cultivos. Os impactos em sua maioria transcendem as propriedades produtoras, impactando bacias hidrográficas e paisagens naturais, através das ações de desmatamento e da poluição do solo e água por insumos agrícolas (ALVES, 2008, p.100).

$\mathrm{O}$ aumento e a consolidação das atividades antrópicas agrícolas ao longo da história brasileira culminaram na degradação dos ecossistemas naturais, levando assim a criação de mecanismos de políticas públicas no intuito de criar diretrizes para conservação e preservação ambiental.

Os riscos ecológicos da monocultura canavieira, provocam danos aos ecossistemas através do uso intensivo de fertilizantes, por exemplo, que é um dos fatores fortemente associados à eutrofização dos rios e lagos, à acidificação dos solos e à contaminação de aquíferos. Em áreas de monocultura o manejo adequado de solos e água é imprescindível, não somente para a manutenção da qualidade ambiental, como também para a qualidade de vida da população (DELGADO, 2011, p.35).

Diversos autores vêm avaliando a magnitude destes impactos, como o estudo realizado por Carvalho (2011, p.238) que avaliou os impactos da monocultura no município de Itapuranga - GO onde a reintrodução da cana-de-açúcar como atividade econômica do município desencadeou diversos problemas ambientais que se tornaram questões de debate público.

Objetivando a preservação, melhoria e recuperação da qualidade ambiental propícia à vida, visando assegurar, no país, condições ao desenvolvimento socioeconômico, aos interesses da segurança nacional e à proteção da dignidade da vida humana, foi criada em 1981 a Política Nacional do Meio Ambiente, que discute sobre a criação de instrumentos no intuito de gerenciar atividades que promovam alterações no meio natural do território brasileiro em virtude da conservação dos ecossistemas naturais (BRASIL, 1981, p.1).

Neste contexto, surge o Zoneamento Ecológico Econômico, regulamentado pelo decreto $\mathrm{n}^{\mathrm{o}}$ 4.297/2002, uma forma de compartimentação de um espaço geográfico, a partir das características físicas e bióticas de seus ecossistemas e suas interações entre si e com os meios socioeconômicos. Seu funcionamento está atrelado a relações políticas-administrativas e conhecimentos técnicos científicos a fim de possibilitar a fundamentação das diretrizes e normas legais que disciplinam o uso dos recursos naturais em dado território (ARAÚJO, 2006, p.135).

O Zoneamento Ecológico Econômico é gerado a partir da combinação de seis áreas de interesses: Zoneamento de interesse e proteção ambiental; Zonas de interesse e recuperação ambiental, Zona de uso especial, Zona Urbana, Zonas de recarga de aquífero e Zonas de potencial agrossilvipastoril.

A elaboração de um zoneamento para o setor agrário é de suma importância uma vez que a expansão da produção agrícola, e consequente cultivo de matérias primas, a fim de fomentar o expansível mercado consumidor, bem como para exportação, têm causado preocupações a respeito da sustentabilidade deste processo produtivo (GOLDEMBERG, COELHO; GUARDABASSI, 2008, p.2090). 
Neste sentido, os Sistemas de Informação Geográfica (SIGs), têm facilitado estas análises e as atividades relacionadas à caracterização, ao diagnóstico e ao planejamento ambiental e urbano, auxiliando em tarefas como a simulação do espaço geográfico e de seus processos naturais, na integração de informações espaciais (RIBEIRO, 1999, p.76).

Considerando que os processos culturais transformadores das paisagens constituem a manifestação integrada dos elementos naturais e culturais, ocasionando mudanças físicas ou culturais na mesma e que o ambiente natural proporciona benefícios para a sociedade de diversos modos ao preservarem a estrutura e função dos ecossistemas (BALMFORD et al., 2002, p.952).

Estes benefícios devem motivar a conservação da natureza diante das pressões econômicas crescentes sobre o ambiente natural, embora a avaliação socioeconômica dos mesmos seja um processo difícil (SANTOS et al., 2001, p.172) e não incorporado na atividade econômica convencional baseada principalmente na análise de mercado. A exploração econômica dos recursos naturais deve combinar de maneira racional o desenvolvimento e as práticas de conservação para resguardar a qualidade ambiental da paisagem local.

Diante disso, o objetivo deste trabalho foi realizar zoneamento da aptidão agrícola do município De Santa Lúcia - SP, com a utilização de Sistemas de Informação Geográficas no intuito de definir as áreas potenciais para o desenvolvimento de tais atividades, a fim de contribuir com o planejamento ambiental da região.

\section{METODOLOGIA}

\section{1 ÁREA DE ESTUDO}

O município de Santa Lúcia localiza-se na região Administrativa Central do Estado de São Paulo, entre as coordenadas $21^{\circ} 42^{\prime} 58^{\prime \prime}$ e $21^{\circ} 37^{\prime} 39^{\prime \prime}$ de latitude sul e $48^{\circ} 10^{\prime} 45^{\prime \prime}$ e $47^{\circ} 54^{\prime} 34^{\prime \prime}$ de longitude oeste, com aproximadamente 154,03 km², tendo como municípios vizinhos Américo Brasiliense, Rincão, Araraquara e São Carlos (IBGE, 2016, p.1).

O município possui uma população de 8.444 habitantes (densidade demográfica de 54 hab. $/ \mathrm{km}^{2}$ ), com grau de urbanização de 95,31\% e taxa de crescimento anual da população em 0,40 (SEADE, 2016, p.1). Pelo tamanho de sua população o município fica isento da obrigatoriedade da elaboração do plano diretor (instrumento básico, previsto no estatuto das cidades, de um processo de planejamento municipal para a implantação da política de desenvolvimento urbano, norteando a ação dos agentes públicos e privado) que prevê a necessidade para município maiores que 20.000 habitantes.

O clima caracteriza-se como tropical de altitude com invernos secos e verões chuvosos, possui relevo de planalto, tem predominância o bioma cerrado, a temperatura média aproxima-se de $21,4^{\circ} \mathrm{C}$ e a média mensal pluviométrica de 106,50mm num total de 1.273,30mm anuais (CEPAGRI, 2016, p.1).

\subsection{MÉTODOS UTILIZADOS}

Os dados primários para a delimitação do município de Santa Lúcia foram adquiridos da base de dados digital do IBGE situação 2014. Para a obtenção da rede de drenagem e das curvas de nível foram adquiridas as cartas topográficas 1:50.000 do Instituto Brasileiro de Geografia e Estatística (IBGE), folhas de Rincão (SF-22-X-D-VI-2) e Porto Pulador (SF-23- V-C- IV-1), escala 1:50.000, datadas no ano de 1973. 
As informações foram inseridas e analisadas em Sistemas de Informações Geográficas (SIGs), sendo utilizados os softwares ArcGis 10.3. Para a elaboração do banco de dados georreferenciado do município, foi adotado o sistema de projeção geográfica Universal Transversa de Mercator, Fuso 23 Sul, datum SIRGAS 2000. Foi utilizada a imagem referente ao satélite LandSat 8- sensor OLI/TIRS bandas 4, 6 e 7, com data de passagem em 16 de março de 2016 referente a órbita 220/75.

Para elaboração do zoneamento agrícola (Figura 1) no município de Santa Lúcia - SP foram utilizados as informações de declividade, áreas de preservação permanente, pedologia e uso e ocupação do solo.

Figura 1 - Fluxograma do método utilizado para realizar a aptidão agrícola canavieira do município de Santa Lúcia/SP

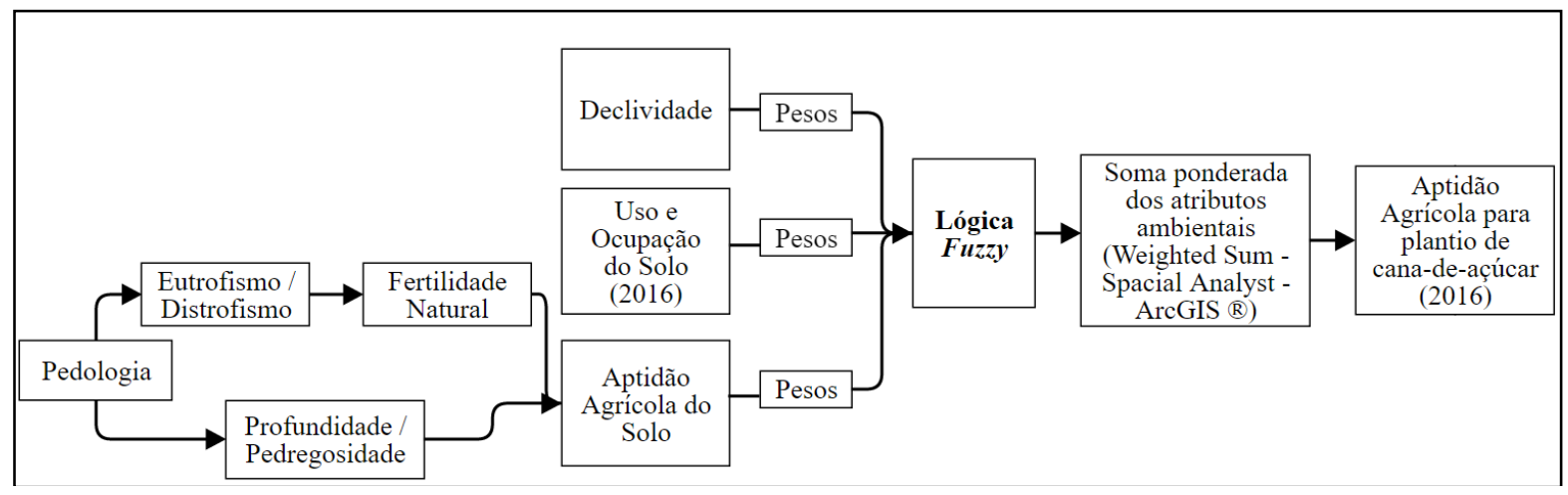

Fonte: Adaptado de Costa et al. (2015, p.950)

Assim como no trabalho de Brunini (2008), a análise constituiu da sobreposição das informações, atribuindo pesos para cada categoria de informação, sendo possível analisar quais os melhores locais para o cultivo das culturas canavieiras. A integração das informações foi realizada através da lógica fuzzy. Tal análise produz resultados mais complexos, promovendo uma aproximação da linguagem humana para as diferentes variáveis analisadas em questão (OPENSHAW; OPENSHAW, 1997). Os pesos atribuídos foram equalizados no intervalo de 0 (muito baixo) a 1 (muito alto).

\subsubsection{Declividade}

O mapa de declividade seguiu a metodologia proposta por Ramalho Filho e Beek (1995, p.34), considerando as aptidões principalmente relacionadas às atividades de mecanização (Tabela 1).

Tabela 1 - Intervalos de declividade, classificação do relevo e suas respectivas aptidões agrícolas

\begin{tabular}{|c|c|c|c|}
\hline \multirow{2}{*}{ Intervalo de declividade } & Classificação do relevo & $\begin{array}{c}\text { Aptidão agrícola a } \\
\text { mecanização }\end{array}$ & Peso \\
\hline $0 \%-3 \%$ & Plano & Alta & 3 \\
\hline $3 \%-8 \%$ & Suavemente ondulado & Alta & 2 \\
\hline $8 \%-13 \%$ & Moderadamente ondulado & Média & 1 \\
\hline $13 \%-20 \%$ & Ondulado & Média & 1 \\
\hline $20 \%-45 \%$ & Forte ondulado & Baixa & 2 \\
\hline
\end{tabular}

Fonte: Adaptado de Ramalho Filho e Beek $(1995$, p. 33, 34) 
De acordo com Ramalho Filho e Beek (1995), as classes de declividade de 0 a 3\% apresentam uma alta aptidão para uso agrícola devido a forma do terreno, por ser plano e facilitar a mecanização no local, as de 3 a $8 \%$ são consideradas como média aptidão devido à uma perda de $25 \%$ ou mais do horizonte superficial, as de 8 a $13 \%$ como média aptidão, pois ainda assim apresentam características favoráveis para o plantio, desde que sejam utilizadas fora dos princípios conservacionistas.

As classes 13 a 20\% possuem aptidão baixa devido as condições do terreno e por ter uma forte tendência à apresentarem erosão. As classes de 20 a $45 \%$ e acima de $45 \%$ devem ser consideradas restritas pois até mesmo mecanização animal é dificultada devido a própria formação do terreno, e por possuir uma grande taxa de suscetibilidade à erosão, sendo imprópria para diversos tipos de agricultura (RAMALHO FILHO; BEEK, 1995, p.34).

\subsubsection{Pedologia}

A classes pedológicas foram delimitadas através Levantamento Pedológico do Instituto Agronômico de Campinas, quadrícula de São Carlos SF.23-Y-A-I E em escala 1:50.000, folha SF.23.Y.A.I, utilizadas para a realização das análises de fertilidade, profundidade favorável e pedregosidade, que seguiram a metodologia proposta por elencado por Brunini (2008, p.8).

Considerou-se como fertilidade alta os solos eutróficos, média para solos distróficos e baixa para solos ácricos, álicos, alumínicos e alíticos. Aspectos de profundidade (favorável ou desfavorável) e pedregosidade (presente ou ausente) fizeram parte da análise.

Solos considerados com profundidade favorável são aqueles que não apresentam limitação física para o crescimento radicular em profundidade, sendo eles os latossolos, argissolos, luvissolos, nitossolos, cambissolos e neossolos quartzarênicos. Para a condição desfavorável, ou seja, aqueles que não possuem condições adequadas para a agricultura em geral, o local de estudo apresentou os solos do tipo neossolos litólicos e plintossolos.

Portanto, uma aptidão agrícola do solo é boa quando se encontra fertilidade natural alta, profundidade favorável e ausência de pedregosidade. Para uma aptidão agrícola do solo média quando se encontra fertilidade natural média e/ou profundidade desfavorável. Por fim, para a aptidão agrícola restrita, considera-se quando ocorrem duas ou mais condições desfavoráveis (Tabela 2).

Tabela 2 - Metodologia para definição da aptidão do solo para o cultivo de cana-de-açúcar

\begin{tabular}{|c|c|c|c|c|}
\hline \multirow{2}{*}{ Fertilidade } & Profundidade & Pedregosidade & Aptidão Agrícola do Solo & Peso \\
\hline \multirow{2}{*}{ Alta } & Favorável & Ausente & Alta \\
\hline Média & Favorável ou Desfavorável & Ausente & Média & 2 \\
\hline Baixa & Favorável ou Desfavorável & Presente ou Ausente & Baixa & 1 \\
\hline
\end{tabular}

Fonte: Brunini (2008, p. 8)

\subsubsection{Uso e cobertura do solo}

A classificação dos usos e cobertura da terra foi baseada no sistema multinível de classificação proposto pelo Manual Técnico de Uso da Terra (IBGE, 2013, p.1), que no nível hierárquico primário (I) 
contemplou quatro classes que indicaram as principais categorias da cobertura terrestre, que foram discriminadas com base na interpretação direta dos dados dos sensores remotos, numa escala mais ampla.

O nível hierárquico secundário (II), explicitou os tipos de usos inseridos no primeiro nível, com um detalhamento mais apurado e preciso da cobertura e o uso da terra em uma escala local e posteriormente o nível hierárquico terciário (III), explicitou os usos propriamente ditos (Tabela 3).

Tabela 3 - Classes de uso e cobertura da terra encontradas para o município de Americana/SP

\begin{tabular}{|c|c|c|}
\hline Classe (I) & Tipo (II) & Descrição (III) \\
\hline $\begin{array}{l}\text { Área Antrópica } \\
\text { não Agrícola }\end{array}$ & Áreas urbanizadas & $\begin{array}{l}\text { Área de adensamento urbano e áreas com instalações rurais (industriais e } \\
\text { domiciliares }\end{array}$ \\
\hline \multirow{5}{*}{$\begin{array}{l}\text { Área Antrópica } \\
\text { Agrícola }\end{array}$} & Cana-de-açúcar & Área de cultivo de Saccharum officinarium $L$. \\
\hline & Citricultura & Área de cultivo de Citros sinensis. \\
\hline & Pastagens & $\begin{array}{c}\text { Área com predomínio de vegetação herbácea (nativa ou exótica), utilizada } \\
\text { para pecuária extensiva. }\end{array}$ \\
\hline & Silvicultura & Área de cultivo homogêneo de Eucalyptus spp ou Pinus spp. \\
\hline & Solo exposto & Área de pousio do solo para cultivo de Saccharum officinarium $L$. \\
\hline Vegetação Natural & Vegetação Nativa & $\begin{array}{c}\text { Área com predomínio de vegetação arbustiva/arbórea, com as formações } \\
\text { vegetais de Floresta Estacional Semidecidual e Cerradão. }\end{array}$ \\
\hline Água & Corpos hídricos & Rios de grande porte, lagos, lagoas e represas. \\
\hline
\end{tabular}

Fonte: Trevisan $(2015$, p.7)

As áreas identificadas com usos agrícolas, silviculturistas, culturas temporárias e áreas descobertas foram consideradas como favoráveis, uma vez que já apresentam empreendimentos agrícolas estabelecidos ou disponibilidade para plantio de culturas agrícolas. As áreas desfavoráveis para o cultivo foram aquelas onde existem áreas urbanizadas ou de mineração. Para as áreas restritas, foram considerados locais onde existam áreas florestais e águas continentais (Tabela 4).

Tabela 4 - Classificação da aptidão do solo perante ao seu uso atual.

\begin{tabular}{c|c|c}
\hline Uso Atual do Solo & Aptidão do Solo & Peso \\
\hline $\begin{array}{c}\text { Áreas agrícolas, silvicultura, culturas temporárias e áreas } \\
\text { descobertas }\end{array}$ & Alta & 2 \\
\hline Áreas urbanizada e de mineração & Média & \\
\hline Áreas florestais e águas continentais & Baixa & 1 \\
\hline
\end{tabular}




\subsubsection{Aptidão Agrícola}

Conforme as características de cada parâmetro analisado, foi atribuído um peso de acordo com as especificidades individualizadas, posteriormente reclassificadas em um intervalo entre 1 a 3 , os quais foram categorizados de acordo com o grau de aptidão agrícola sendo: (1= Baixa, 2 = Média e 3 = Alta). A partir desta reclassificação foi aplicada a função Álgebra de Mapas disponível no software ArcGis 10.3, correspondente a seguinte equação transcrita por Costa et al. (2015, p.950):

Aptidão agrícola $=(A+U+D) / 3$

$\mathrm{D}=$ Declividade;

A = Aptidão agrícola do solo;

$\mathrm{U}=$ Uso e cobertura da terra.

A análise de aptidão agrícola do município considerou metodologia proposta por Costa et al. (2015, p.950) que leva em consideração o equilíbrio entre os componentes físicos, bióticos e abióticos do ambiente (Tabela 5).

Tabela 5 - Classes de aptidão agrícola do município de Santa Lúcia - SP e suas respectivas áreas ocupadas

\begin{tabular}{|c|c|c|}
\hline \multicolumn{1}{c|}{ Aptidão Agrícola } & Peso & Peso reescalonado em Fuzzy \\
\hline Alta & $2-3$ & $0,66-1$ \\
\hline Média & $1-2$ & $0,33-0,66$ \\
\hline Baixa & $0-1$ & $0-0,33$ \\
\hline
\end{tabular}

Fonte: Os autores

\section{RESULTADOS E DISCUSSÃO}

A análise de declividade para o município de Santa Lúcia - SP, verificou que, majoritariamente, o relevo do município possui aspecto plano e suavemente ondulado (Figura 2), compreendendo $12.327,40$ hectares da área municipal total. Isso implica que 79,92\% da área possui declividade entre os intervalos e 0 a $8 \%$, ou seja, grande parte da área possui alta aptidão agrícola quando considerado apenas o fator declividade (Tabela 6).

Em muitos casos, é a topografia do terreno, especialmente a declividade, o principal condicionador de sua capacidade de uso. O Código Florestal Brasileiro (Lei $\mathrm{N}^{\mathrm{o}}$ 12.651/12) considera as áreas de encostas ou partes destas, com declividade superior a $45^{\circ}$ como áreas de preservação permanente, no intuito de função preservar os recursos hídricos, a paisagem, a estabilidade geológica, a biodiversidade, o fluxo gênico de fauna e flora, proteger o solo e assegurar o bem-estar das populações humanas. 
Tabela 6 - Classes de relevo, seus intervalos de declividade correspondentes e suas respectivas áreas ocupadas

\begin{tabular}{|c|c|c|c|}
\hline \multicolumn{1}{|c|}{ Classes de Relevo } & Intervalo & Área (Ha) & Porcentagem \\
\hline Plano & $0-3 \%$ & $6.291,93$ & $30,79 \%$ \\
\hline Suavemente ondulado & $3-8 \%$ & $6.035,54$ & $13 \%$ \\
\hline Ondulado & $8-13 \%$ & $2.247,85$ & $4,10 \%$ \\
\hline Moderadamente ondulado & $13-20 \%$ & 640,22 & $1,35 \%$ \\
\hline Forte ondulado & $20-45 \%$ & 207,76 & $<1 \%$ \\
\hline Montanhoso e escarpado & $>45 \%$ & 0,30 & $<$ \\
\hline
\end{tabular}

Fonte: Os autores

Apresentam-se principalmente na região oeste do município, uma maior ocorrência do aspecto ondulado e moderadamente ondulado, apresentando, portanto, declividades entre 8 e $20 \%$. Na área central do município, o relevo mostrou-se com aspectos moderados e fortemente ondulados, compreendidos entre 20 e $45 \%$.

Figura 2 - Mapas dos intervalos de declividade e de suas classificações de relevo do município de Santa Lúcia - SP

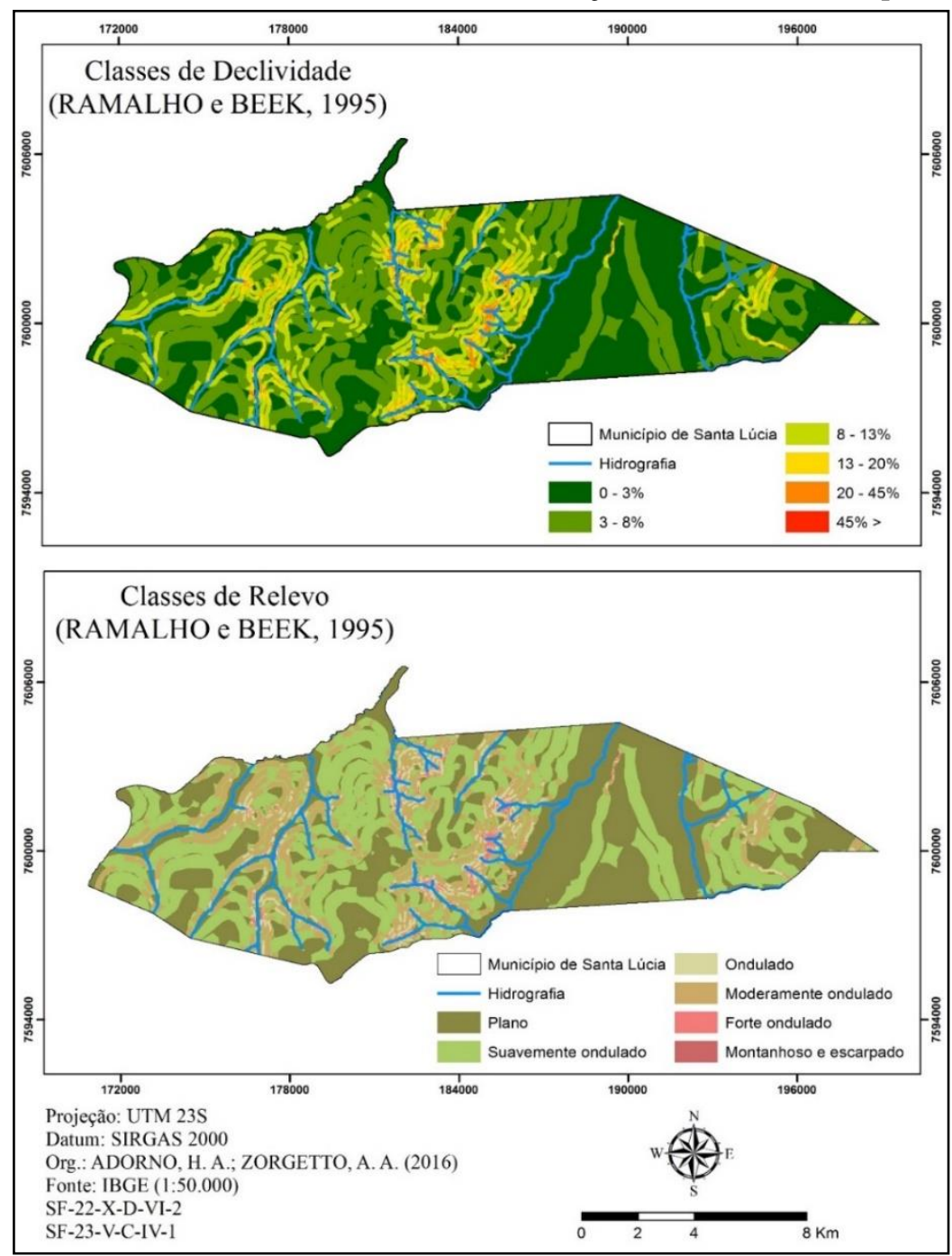

Fonte: Os autores 
Este fato torna essa área inadequada para a mecanização pois segundo Gomes e Montaño (2012, p.10), a ocupação das áreas que apresentam declividades superiores a $20 \%$ inviabiliza a colheita mecanizada além de se mostrarem problemáticas devido às restrições ambientais, pois em sua maioria estão associadas as áreas de vegetação natural e áreas próximas aos recursos hídricos.

A partir da classificação das classes pedológicas (Figura 3), observa-se que dentro dos limites municipais, existe a ocorrência de Argissolo Vermelho-Amarelo, Latossolo Vermelho, Latossolo Vermelho-Amarelo e Gleissolo Háplico.

Figura 3 - Mapas pedológicos, de eutrofismo dos solos, de fertilidade natural e de aptidão agrícola para o município

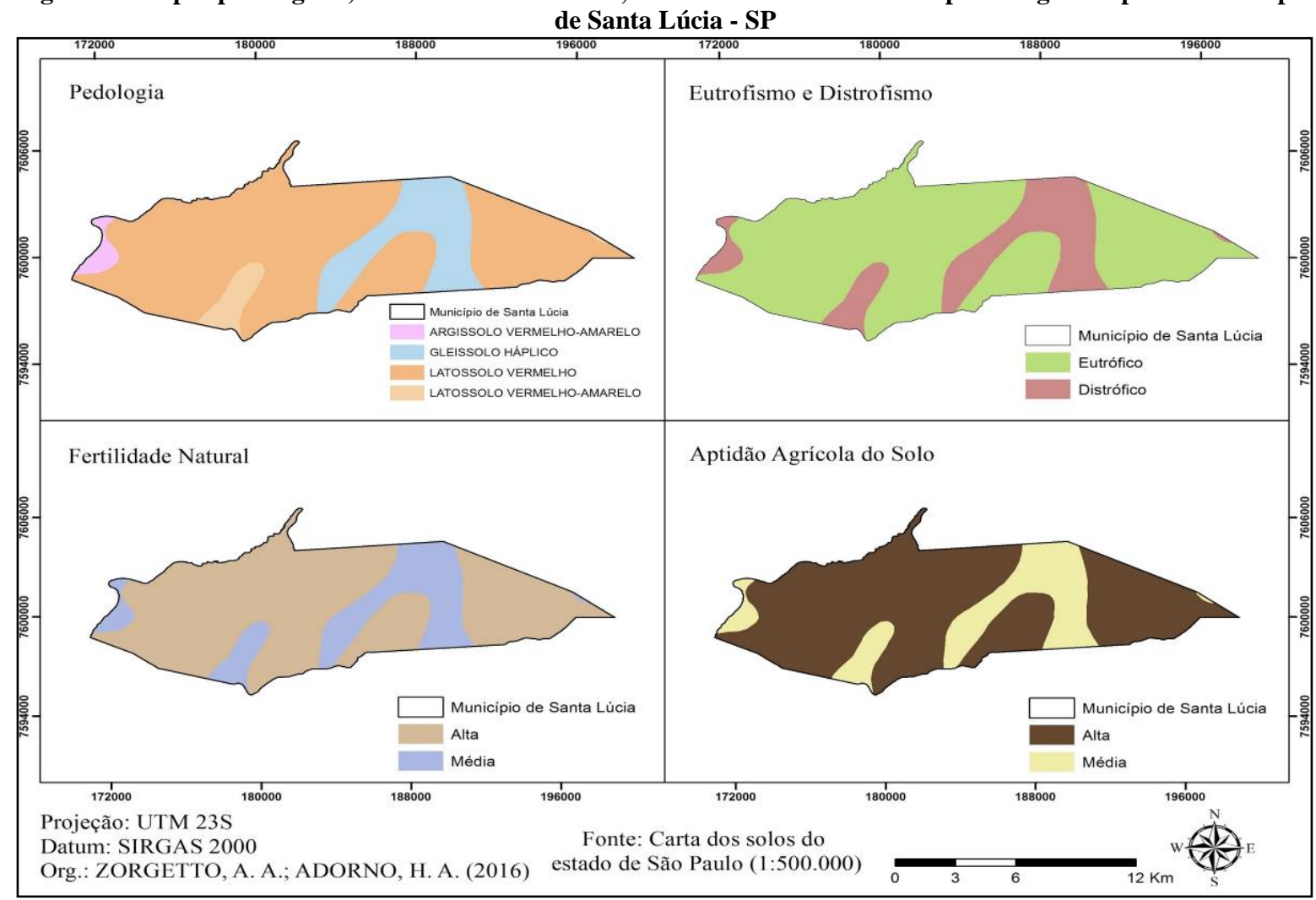

Fonte: Os autores

A categorização de suas respectivas fertilidades naturais, profundidades e pedregosidades foi associada de acordo com cada tipo de solo encontrado. Estas características foram utilizadas para determinar a aptidão agrícola do solo.

Dentro dos limites municipais, observa-se a ocorrência apenas de solos eutróficos ou distróficos, não ocorrendo a presença de solos ácricos, álicos, alumínicos ou alíticos. Portanto, a fertilidade natural do solo no município variou entre alta e média, sendo mais um fator contribuinte para uma alta aptidão agrícola.

Os solos presentes no município tanto para profundidade e pedregosidade possuem condições altas para a agricultura, onde todos os tipos de solo presentes no município não apresentam restrições físicas a livre penetração radicular, sendo assim considerados neste critério como favoráveis.

A análise do uso e cobertura da terra para o ano de 2016, demonstra que grande porcentagem do município está atualmente destinada às culturas agrícolas (Figura 4), principalmente a cana-de-açúcar, totalizando $10.788,47$ hectares, o que equivale a aproximadamente $69,9 \%$ da área total do município (Tabela 7). 
Figura 4 - Uso e cobertura da terra para o ano de 2016 do município de Santa Lúcia - SP

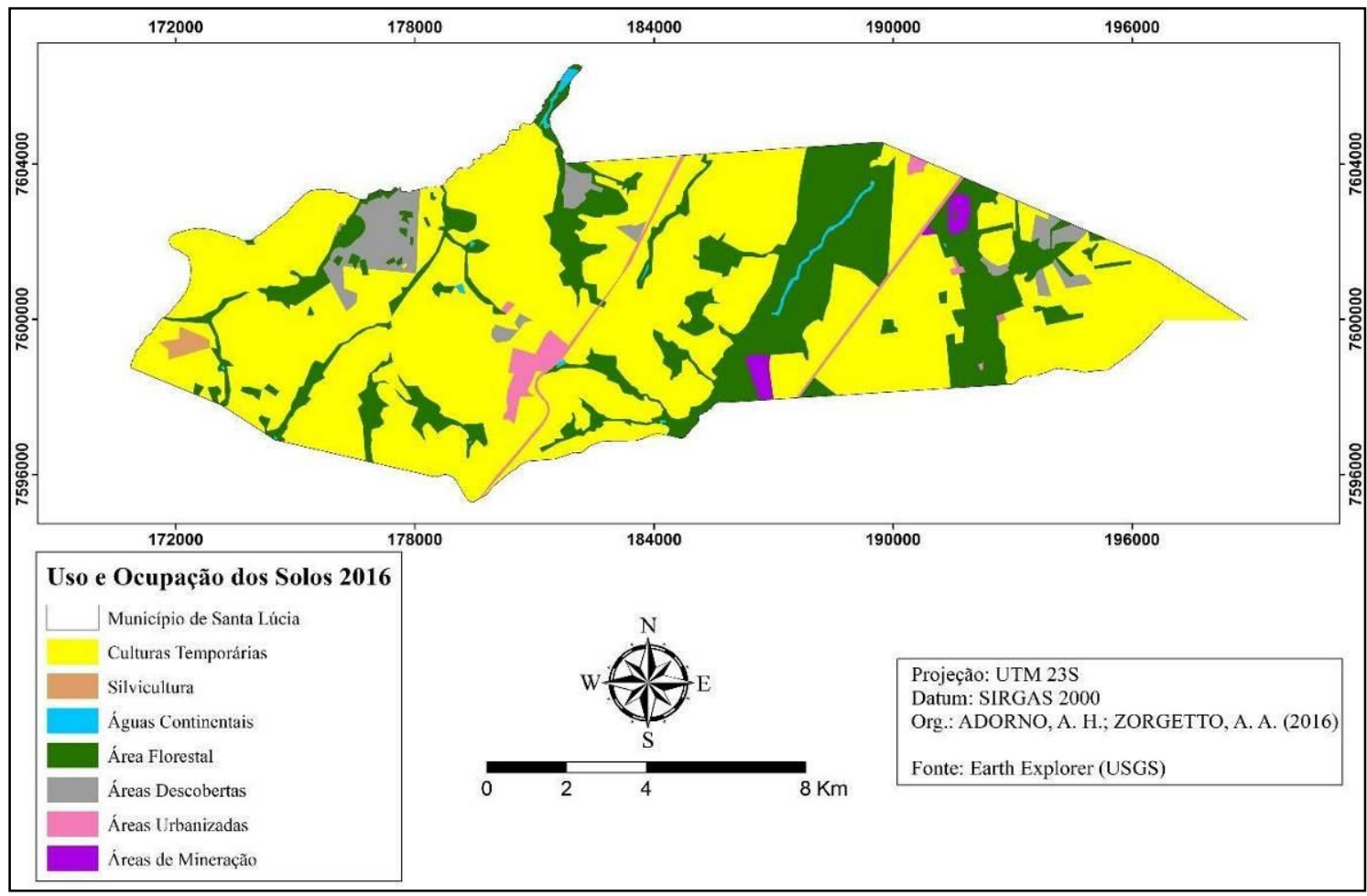

Fonte: Os autores

Esse fato coincide com o cenário paulista, sendo o estado de São Paulo, mais precisamente o interior paulista, o maior produtor de cana-de-açúcar do Brasil. Este título remete ao crescimento do mercado interno e de condições favoráveis ao seu cultivo, como por exemplo, ser o estado com mais terras férteis, que permite a produtividade média maior do que em outras regiões e pelo fato de possuir desenvolvido setor de bens de produção para a cultura canavieira (NATALE NETTO, 2007, p.210).

O cenário observado é semelhante a estudos realizados com esta temática em outras regiões (TREVISAN; MOSCHINI, 2015, p.10; FISHER, 2008, p.35; DOS SANTOS, 2011, p.55), os quais também evidenciaram a expansão do cultivo da cana-de-açúcar e a supressão de áreas de vegetação nativa.

Tabela 7 - Usos do solo e suas respectivas áreas ocupadas.

\begin{tabular}{|c|c|c|}
\hline \multicolumn{1}{|c|}{ Usos do Solo } & Área (Ha) & Porcentagem \\
\hline Culturas temporárias & $10.788,47$ & $69,9 \%$ \\
\hline Silvicultura & 53,89 & $0,35 \%$ \\
\hline Águas continentais & 67,31 & $0,43 \%$ \\
\hline Áreas florestais & $3.549,91$ & $23 \%$ \\
\hline Áreas descobertas & 573,68 & $3,71 \%$ \\
\hline Áreas urbanizadas & 294,18 & $1,91 \%$ \\
\hline Áreas de mineração & 106,65 & $0,7 \%$ \\
\hline
\end{tabular}

Fonte: Os autores 
Tendo estes aspectos, a análise das áreas de aptidão agrícola foi realizada (Figura 5), em uma escala de alta à restrita. Grande parte da extensão municipal possui aptidão agrícola alta e média. Um dos fatores que influenciaram este resultado foi o fato de principalmente o relevo do município mostrarse plano ou suavemente ondulado, classificações consideradas favoráveis à agricultura mecanizada.

Outro fator relevante para o resultado são as grandes parcelas do município onde já existe o plantio de culturas temporárias, sendo que a mais observada é a cana-de-açúcar. Estas áreas onde o plantio já é existente e que não existem impedimentos legais para o cultivo receberam pesos máximos quando foram feitas as sobreposições, portanto são consideradas como aptidão agrícola alta e favorável.

Nota-se que aproximadamente $36 \%$ da área total do município possui baixa aptidão paras as atividades agrícolas, pois são locais associados as áreas de preservação permanente e a parcelas onde localizam-se o Gleissolo Háplico, que apresenta uma série de limitações para o uso agrícola principalmente por terem baixa quantidade de oxigênio (excesso de água), por ter baixa fertilidade e por possuir barreiras à mecanização. Esse tipo de solo deve preferencialmente ser destinado para áreas de preservação, portanto, são áreas consideradas como baixa aptidão tanto pelas suas características como pela sua importância (Tabela 8).

Figura 5 - Aptidão agrícola considerando as áreas legalmente restritas do município de Santa Lúcia - SP

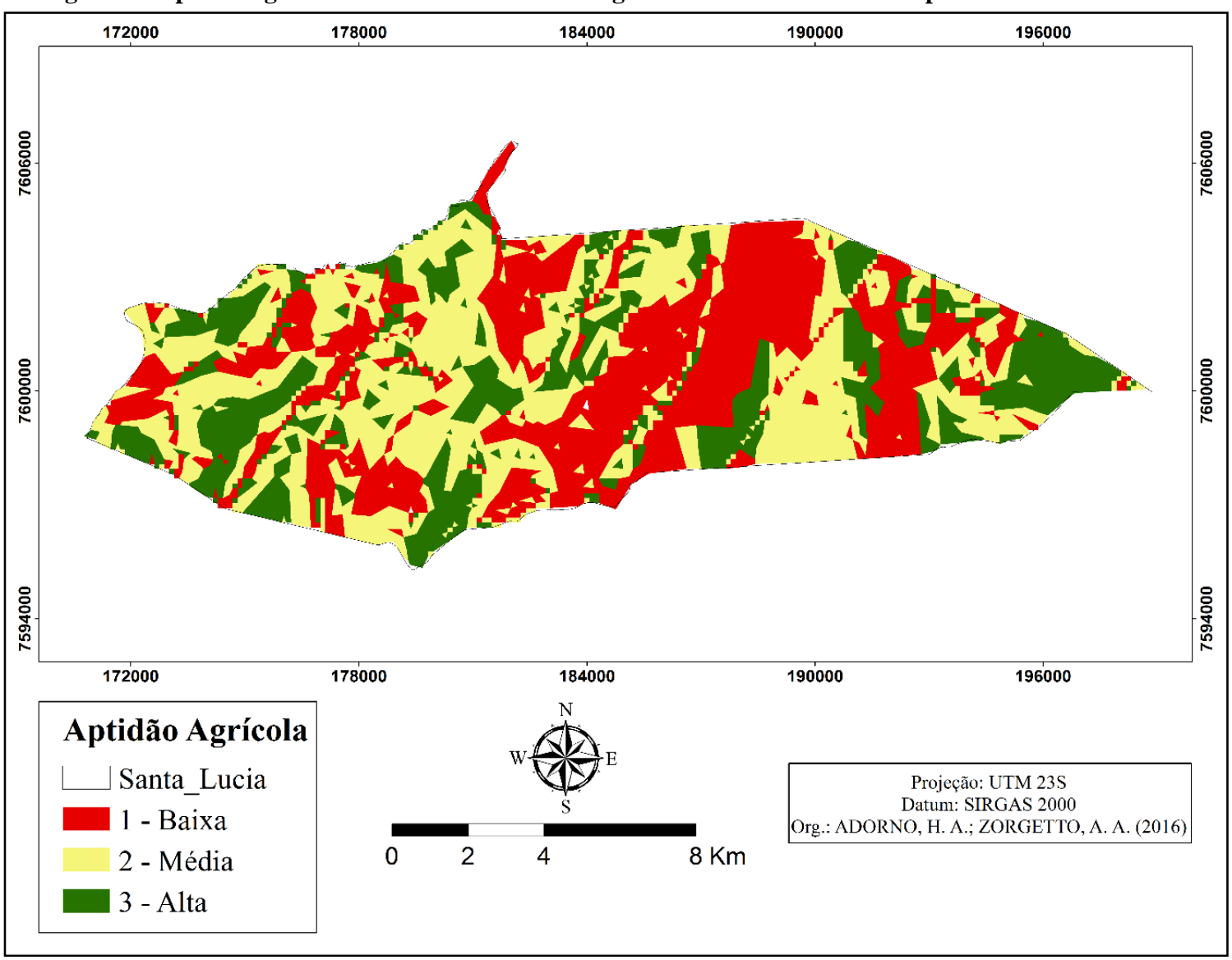

Fonte: Os autores

As áreas de alta restrição juntamente com o uso e cobertura da terra atual, percebe-se que, de fato, ocorrem usos proibitórios bem como não aconselhados nestas regiões. Verifica-se que 1.706,81 hectares, que corresponde a aproximadamente $51,14 \%$ do total das áreas restritivas, como áreas de preservação permanente, são ocupados por culturas temporárias. 
Tabela 8 - Aptidão agrícola do município de Santa Lúcia - SP e sua respectiva porcentagem de área ocupada

\begin{tabular}{|c|c|c|}
\hline Aptidão Agrícola & Área (Ha) & Porcentagem \\
\hline Baixa & $5.569,31$ & 36,30 \\
\hline Média & $3.674,11$ & 23,95 \\
\hline Alta & $6.098,96$ & 39,75 \\
\hline
\end{tabular}

Fonte: Os autores

Contudo, 1.566,66 hectares, aproximadamente 47\% destas áreas totais, são ocupadas por áreas florestais. Compreendendo o restante destas áreas (2\%) estão, em ordem decrescente, as águas continentais, áreas urbanizadas, áreas descobertas e áreas de mineração. Esse fato reforça a necessidade de monitoramento e fiscalização mais intensa de áreas restritivas, como áreas de preservação permanente, áreas que contém Gleissolo Háplico, florestas naturais e águas continentais.

Áreas com alta aptidão agrícola são menores em relação a áreas de média e baixa aptidão agrícola no município de Santa Lúcia. Porém, ao analisar o mapa de uso e cobertura do solo, observa-se que grande extensão do município é dominado por culturas temporárias, sendo constituído principalmente por cana-de-açúcar. No entanto, o predomínio de culturas de cana-de-açúcar traz malefícios para o ambiente.

Os principais impactos ambientais negativos gerados pelo cultivo excessivo de cana-de-açúcar (principal atividade do município e região) relacionam-se com a redução da biodiversidade gerada por desmatamento e monocultura; avanço agrícola para áreas de proteção ambiental; redução da qualidade e contaminação do solo e águas superficiais e subterrâneas por efluentes, causados por adubos químicos; comprometimento de qualidade e disponibilidade hídrica; compactação do solo pelo tráfego de maquinários; potencial de erosão do solo e assoreamento de corpos hídricos próximos de áreas canavieiras; redução da qualidade do compartimento do ar, devido a queimadas sem controle; e danos para a flora e fauna devido a supressão de habitats.

Tendo em vista este crescimento descontrolado e impactos gerados pelo cultivo de cana-deaçúcar, como no caso de Santa Lúcia, observa-se que é necessário o monitoramento constante e preciso sobre essas áreas. No Brasil, sabe-se que a agricultura predomina o uso e ocupação/cobertura do solo. Quantificar áreas destinadas à agricultura e áreas de proteção integral ou de uso sustentável é de extrema valia para o cenário nacional. Obter o controle sobre o avanço da cana-de-açúcar é necessário não somente para escalas pequenas, como cidades, mas sim para escalas maiores, como um Estado e para o país como um todo.

Sabendo que a matriz paisagística de Santa Lúcia é a agricultura, o zoneamento, por sua vez, possui papel importante como instrumento de manejo de áreas agrícolas. A proposta de um zoneamento é benéfica pois com ela é possível compreender o mundo real de outra maneira, de forma que se produz uma fonte de dados que serão gerenciados posteriormente, que seja possível realizar várias análises, bem como o zoneamento e avaliação de áreas agrícolas. Por fim, os profissionais envolvidos na tomada de decisão e responsáveis por executar atividades são auxiliados com os produtos gerados por análises em Sistemas de Informações Geográficas, ou seja, pelos mapas como declividade, uso e cobertura do solo e aptidão agrícola (COELHO, 2005, p.46). 


\section{CONSIDERAÇÕES FINAIS}

O mapa de aptidão agrícola do município de Santa Lúcia - SP permitiu analisar que grande parte de sua extensão territorial possui uma aptidão agrícola alta e média. Os locais que possuem restrições legais ou que possuem baixa aptidão para plantio devem receber um reordenamento de seus usos do solo, destinando-se para o desenvolvimento áreas de recuperação ambiental.

Uma outra alternativa para esses problemas é a implantação diversificada de culturas, aproveitando melhor o espaço e impactando menos os recursos naturais e a biodiversidade ali presente. A agricultura familiar e o sistema agroflorestal são técnicas novas de agricultura que vem se desenvolvendo no país e que trazem uma filosofia de maior preservação do meio natural e produção orgânica de alimentos. Portanto, buscam atingir a melhor utilização do solo e a distribuição mais igualitária das terras e da renda gerada.

Tornam-se cada vez mais necessárias as ações de planejamento que almejem um modelo de desenvolvimento que leve em consideração toda esta temática, incluindo todos os agentes socioambientais, econômicos e culturais, focando não apenas nos problemas, mas em suas causas, reforçando a ideia de necessidade de desenvolvimento que relacione o crescimento econômico e a conservação dos ecossistemas.

As ferramentas de geoprocessamento como o ArcGIS 10.3 e os mecanismos de sensoriamento remoto são importantes instrumentos de fiscalização, estudo e monitoramento de ambientes que são destinados a agricultura em geral, principalmente em países como o Brasil, onde a matriz econômica advém da agricultura.

\section{REFERÊNCIAS}

ALVES, F. Certificação socioambiental para a agricultura: desafios para o setor sucroalcooleiro. Imaflora; São Carlos: EdUFSCar, 2008,314p.

ARAÚJO, F. C. Reforma Agrária e Gestão Ambiental: Encontros e Desencontros,2006. 242f. Dissertação de (Mestrado em Desenvolvimento Sustentável) UNB: Centro de Desenvolvimento Sustentável - Brasília/DF,2006.

BALMFORD, A.; BRUNER, A.; COOPER, P.; COSTANZA, R.; FARBER, S.; GREEN, R.E.; JENKINS, M.; JEFFERISS, P.; JESSAMY, V.; MADDEN, J.; MUNRO, K.; MYERS, N.; NAEEM, S.; PAAVOLA, J.; RAYMENT, M.; ROSENDO, S.; ROUGHGARDEN, J.; TRUMPER, K.; TURNER, R. K. Economic Reasons for Conserving Wild Nature. Science, n.297, p. 950 - 953, 2002.

BRUNINI, O. O zoneamento de culturas bioenergéticas no Estado de São Paulo. 2008. Disponível em: <www.ciiagro.sp.gov.br/zoneamento/2008>. Acesso em: 17 nov. 2016.

BRASIL. República Federativa do Brasil. LEI N 6.938, de 31 de agosto de 1981, 1981. Disponível em: <http://www.planalto.gov.br/ccivil_03/leis/L6938.htm>. Acesso em: 13 abr. 2017.

CARVALHO, S. P.; MARIN, J. O. B. Problemas ambientais desencadeados pelo plano nacional de agroenergia: o caso de Itapuranga, Goiás. Interações (Campo Grande), v. 12, n. 2, p. 235-247, 2011.

CEPAGRI. Centro de Pesquisas Meteorológicas e Climáticas Aplicadas à Agricultura. Clima dos municípios paulistas. 2016. Disponível em: <http://www.cpa.unicamp.br/outrasinformacoes/clima_muni_224.html>.Acesso em: 17 nov. 2016. 
COELHO, A. Agricultura de Precisão: manejo da variabilidade espacial e temporal dos solos e culturas. Agricultura, v. 1518, n. 4277, p. 46, 2005.

COSTA, WILMER; PIGA, G.; MORAES, C.; DORICI, M.; SANGUINETTO, C.; LOLLO, A; MOSCHINI, E; LORANDI, R; OLIVEIRA, J. Fragilidade ambiental e escassez hídrica em bacias hidrográficas: Manancial do Rio das Araras - Araras, SP. Revista brasileira de Recursos Hídricos, vol $^{\circ} 20, n^{\circ} .4$, p. $946-958,2015$.

DECRETO ESTADUAL Nº 39.473. Estabelece Normas De Utilização Das Várzeas No Estado De São Paulo,1994. Disponível em:

<licenciamento.cetesb.sp.gov.br/legislacao/estadual/decretos/1994_Dec_Est_39473.pdf >. Acesso em: 17 nov. 2016.

DELGADO, N. A. S. M. Geoprocessamento na análise da vulnerabilidade ambiental desencadeada pela monocultura de cana-de-açúcar na bacia do distrito Santa Olímpia (Piracicaba/SP). 2011,56f. Trabalho de Conclusão de Curso (Bacharelado em Engenharia Ambiental) UNESP, 2011.

DOS SANTOS, R.M. Padrão temporal e espacial das mudanças de usos da terra e cenários para a conservação da biodiversidade regional do município de São Félix do Araguaia, MT.

2011.153f. Tese (Doutorado em Ecologia de Recursos Naturais) - Universidade Federal de São Carlos, São Carlos, 2011.

FISHER, G. Land use dynamics and sugarcane production. IN: Zuurbier, P.; Van De Vooren, J (Ed.). Sugarcane ethanol: contributions to climate change mitigation and the environment. Wageningen Academic Publishers, 1 ${ }^{\text {a }}$ ed, v.1, p. 29-62, 2008,

GOES, T.; MARRA, R.; SILSA, G.S. Setor sucroalcooleiro no Brasil situação atual e perspectivas. Revista de Política Agrícola, v. 17, n. 2, p. 39-51, 2008.

GOLDEMBERG, J.; COELHO, S. T.; GUARDABASSI, P. The sustainability of ethanol production from sugarcane. Energy policy, v. 36, n. 6, p. 2086-2097, 2008.

GOMES, P. M.; MONTAÑO, M. A expansão da cana-de-açúcar e o zoneamento agroambiental do setor sucroalcooleiro do estado de São Paulo. Anais. Conferência da rede de língua portuguesa de avaliação de impactos, 2012.

HERZ, R.; DE BIASI, M. Critérios e legendas para macrozoneamento costeiro. Ministério da Marinha/Comissão Interministerial para Recursos do Mar. Brasília: Ministério do Meio Ambiente, 1989,50p.

IBGE. Instituto Brasileiro De Geografia E Estatística. Conceitos e Limites territoriais. Disponível em: <www.cidades.ibge.gov.br/xtras/perfil.php?lang=\&codmun=354690\&search=sao-paulo|santalucia>. Acesso em: 17 nov. 2016.

IBGE. Instituto Brasileiro De Geografia E Estatística. Manuais Técnicos em Geociências. 3. ed. Rio de Janeiro: IBGE, 2013. 171 p.

IBGE. Instituto de Geografia e Estatística. Divisão territorial brasileiro e limites territoriais: IBGE cidades - Santa Lúcia,2016. Disponível em: <http://cidades.ibge.gov>. Acesso em: 17 nov. 2016.

JUNIOR, A. C. Análise de fragilidade ambiental com métodos multicritério-críticas e proposta metodológica. 2011,149f. Tese (Doutorado em Engenharia Urbana). Universidade Federal de São Carlos, 2011. 
NATALE NETTO, J. A saga do álcool: fatos e verdades sobre os 100 anos do álcool combustível em nosso país. 1. ed. Osasco, SP: Novo Século, 2007, 343 p.

OPENSHAW, S.; OPENSHAW, C. Artificial Intelligence in Geography. Chichester: John Wiley, 1997,300p.

RAMALHO-FILHO, A.; BEEK, K. J. Sistema de avaliação da aptidão agrícola das terras. 3. ed. Rio de Janeiro: EMBRAPA-CNPS, 1995, 65 p.

RIBEIRO, F.L.; CAMPOS, S.; PIROLI, E.L; SANTOS, T.G.; CARDOSO, L.G. Uso da terra do Alto rio pardo, obtido a partir da análise visual IN: Anais. I Ciclo de Atualização Florestal do Conesul Santa Maria: UFSM, 1999. v. único, p. 75-81, 1999.

SANTOS, J.E.; NOGUEIRA, F.; PIRES, J.S.R.; OBARA, A.T.; PIRES, A.M.Z.C.R. The value of the Ecological Station of Jatai's ecosystem services and natural capital. Revista Brasileira de Biologia, n.61, p.171-190, 2001.

SEADE. Fundação Sistema Estadual de Análise de dados. Perfis municipais. 2016. Disponível em: <http://produtos.seade.gov.br/produtos/perfil/>. Acesso em: 17 nov. 2016.

SILVA, M. A. M.; MARTINS, R. C. A degradação social do trabalho e da natureza no contexto da monocultura canavieira paulista. Sociologias, p. 196-240, 2010.

TREVISAN, D. P. Análise das variáveis ambientais causadas pelas mudanças dos usos e cobertura da terra do município de São Carlos, São Paulo, Brasil. São Carlos, 2015. 80 f. Dissertação (Mestrado) - Universidade Federal de São Carlos, São Carlos, 2015.

TREVISAN, D. P.; MOSCHINI, L. E. Dinâmica de Uso e Cobertura da Terra em Paisagem no Interior do Estado de São Paulo: Subsídios para o planejamento. Fronteiras: journal of social, technological and environmental science, v. 4, p. 16-30, 2015.

\section{AGRADECIMENTOS}

A Fundação de Amparo à Pesquisa do Estado de São Paulo (FAPESP) Processo: 2015/19918-3 pelo apoio na realização do trabalho. 